14 - Murakami M, Sugita A, Hamasaki M. The vas deferens in man and monkey: spermiophagy in its ampulla. In : Atlas of human reproduction by scanning electron microscopy. 1982 E. Hafez, P Keneman eds, Lancaster, Boston, the Hague MTP Press limited, pp : 187-195

15 - Nagdas SK, Skudlarek M, Orgebin-Christ MC, Tulsiani DRP : Biochemical alterations in the proacrosin-acrosin system during epididymal maturation of the rat spermatozoa. J Androl, 1992, 13: 36-43.

16- Orgebin-Christ MC. Physiologie de l'épididyme et maturation du sperme: état actuel des connaisances. Contr. Fertil Sex, 1986; 14: 487-495.

17 - Robaire B, Hermo L : Efferents ducts, epididymis and vas deferens: structure, functions and their regulation. In : The Physiology of Reproduction, E. Knobil, J. Neil et al eds, Raven Press New York, 1988, 1 : 999-1080.

18 - Ross P, Kan FWK, Antaki P, Vigneault N, Chapdelaine A, Roberts KD : Protein synthesis and secretion in the human epididymis and immunoreactivity with sperm antibodies. Mol. Reprod. Dev. 1990, $26: 1223$.

19 - Rowley MJ, Teshima F, Heller CG : Duration of transit of spermatozoa through the human male ductulal system. Fertil. Steril. 1970, 21: 390-395.

20 - Schoysman RJ, Bedford JM : The role of the human epididymis in sperm maturation and sperm storage as reflected in the consequences of epididymovasostomy. Fertil Steril, 1986, 46: 293-299.

21 - Silber SJ : Apparent fertility of human spermatozoa from the caput epididymis. J Androl, 1989. 10: 263-269.

22 - Taragnat $\mathrm{C}$, Berger $\mathrm{M}$, Jean $\mathrm{Cl}$. Identification and androgen-dependence of proteins in the mouse vas deferens. Int J Androl, 1986, 9: 299-311.

23 - Yeung $\mathrm{CH}$, Cooper TG, Senge $\mathrm{T}$ : Histochemical localization and quantification of $\alpha$-glucosidase in the epididymis of men and laboratory animals. Biol Reprod, 1990, 42 : 69-676.
RESUME : Le conduit épididymo-déférentiel assure non seulement le transport mais l'acquisition du pouvoir fécondant des spermatozoïdes. Les fonctions du compartiment épithélial jouent un rôle déterminant dans la composition du liquide intraluminal dans lequel les spermatozoïdes subissent des modifications structurales, biochimiques et métaboliques. Durant le transit dans l'épididyme, les spermatozoïdes acquièrent leur mobilité et l'aptitude à se fixer sur la zone pellucide et à féconder l'ovocyte. Chez l'homme, la maturation des spermatozoïdes peut se produire dans la portion plus proximale du conduit épididymaire. La régulation des fonctiolls de l'épididyme et du canal déférent ainsi que la maturation des spermatozoïdes sont sous le contrôle des androgènes. Mots clés : Epididyme - Canal déférent - Physiologie - Maturation des spermatozoïdes. Andrologie, 1992, 2 : 44-47.

\title{
BOURSES DE VOYAGE OFFERTES A DES JEUNES PAR L'ISA POUR SE RENDRE AU CONGRES MONDIAL D'ANDROLOGIE DE TOKYO
}

\section{(2 au 6 Mai 1993)}

L'International Society of Andrology offre 20 bourses de voyage de 750 \$ US pour se rendre à Tokyo. Elles sont réservées à des scientifiques jeunes, avec une préférence pour ceux venant des pays en voie de développement, mais possibilité d'attribution à des européens. La condition pour l'obtention de la bourse est la soumission d'un mini-poster pour le congrès. Les boursiers seront sélectionnés d'après la qualité scientifique de leur résumé. La date limite pour l'envoi des résumés est le 31 Décembre 1992.

Le premier auteur du mini-poster doit préciser son souhait de participer à la compétition pour l'obtention d'une bourse dans une lettre jointe au mini-poster et au formulaire d'inscription. Les bénéficiaires seront informés avant le congrès. 